\title{
The importance of aboveground-belowground interactions on the evolution and maintenance of variation in plant defense traits
}

\author{
Moniek van Geem ${ }^{1}{ }^{*}$, Rieta Gols ${ }^{2}$, Nicole M. van Dam ${ }^{3}$, Wim H. van der Putten ${ }^{1,4}$, Taiadjana Fortuna ${ }^{1}$ and \\ Jeffrey A. Harvey ${ }^{1,5}$
}

${ }^{1}$ Department of Terrestrial Ecology, Netherlands Institute of Ecology (NIOO-KNAW), Wageningen, Netherlands

${ }^{2}$ Laboratory of Entomology, Wageningen University, Wageningen, Netherlands

${ }^{3}$ Radboud University Nijmegen, Institute for Water and Wetland Research, Nijmegen, Netherlands

${ }^{4}$ Laboratory of Nematology, Wageningen University, Wageningen, Netherlands

${ }^{5}$ Department of Ecological Sciences, Animal Ecology, VU University, Amsterdam, Netherlands

\section{Edited by:}

Roxina Soler, Wageningen University, Netherlands

\section{Reviewed by:}

Scott Nicholas Johnson, University of Western Sydney, Australia

Tibor Bukovinszky, Wageningen University and Research Centre, Netherlands

\section{*Correspondence:}

Moniek van Geem, Department of Terrestrial Ecology, Netherlands Institute of Ecology (NIOO-KNAW), Droevendaalsesteeg 10, 6708 PB Wageningen, Netherlands e-mail:m.vangeem@nioo.knaw.nl
Over the past two decades a growing body of empirical research has shown that many ecological processes are mediated by a complex array of indirect interactions occurring between rhizosphere-inhabiting organisms and those found on aboveground plant parts. Aboveground-belowground studies have thus far focused on elucidating processes and underlying mechanisms that mediate the behavior and performance of invertebrates in opposite ecosystem compartments. Less is known about genetic variation in plant traits such as defense as that may be driven by above- and belowground trophic interactions. For instance, although our understanding of genetic variation in aboveground plant traits and its effects on community-level interactions is well developed, little is known about the importance of aboveground-belowground interactions in driving this variation. Plant traits may have evolved in response to selection pressures from above- and belowground interactions from antagonists and mutualists. Here, we discuss gaps in our understanding of genetic variation in plant-related traits as they relate to aboveground and belowground multitrophic interactions. When metabolic resources are limiting, multiple attacks by antagonists in both domains may lead to trade-offs. In nature, these tradeoffs may critically depend upon their effects on plant fitness. Natural enemies of herbivores may also influence selection for different traits via top-down control. At larger scales these interactions may generate evolutionary "hotspots" where the expression of various plant traits is the result of strong reciprocal selection via direct and indirect interactions. The role of abiotic factors in driving genetic variation in plant traits is also discussed.

Keywords: genetic variation, aboveground-belowground interactions, herbivore, natural enemy, plant defense, selection pressures, Brassica oleracea

\section{INTRODUCTION}

Of the many traits possessed by plants that are closely tied with their growth, survival and fitness, those relating to defence have been especially well studied over many years (see reviews by Karban and Baldwin, 1997; Schoonhoven etal., 2005). Defences in plants are often divided into direct and indirect defenses. Direct defenses are aimed directly at the attackers, such as herbivores, and include morphological (e.g., trichomes or sticky glands) and chemical (toxic secondary compounds) traits that interfere with colonization, feeding, and development of the herbivore. For example, toxic secondary compounds can act as feeding deterrents or negatively alter the performance of a herbivore through increased mortality, slower growth rates, or reduced fitness (Schoonhoven et al., 2005). Indirect defenses are aimed at promoting the efficiency of natural enemies, such as predators or parasitic wasps (parasitoids) that kill the herbivores and thus reduce their damage to the plant. Indirect defenses may also be morphological (e.g., domatia) or chemical (e.g., the production of attractive volatiles, energy sources). Both direct and indirect defenses are expressed constitutively in many plants, meaning that they are always expressed whereas in others they are often inducible, meaning that initial levels are low but increase after attack (Karban and Baldwin, 1997). These traits are often species(or even genotype) specific, and are assumed to depend on the predictability of attacks from antagonists and susceptibility of plants to these attacks.

Unlike most terrestrial biota, the vast majority of plants occupy two connected "compartments" - the open air and soil - that differ in many biotic and abiotic properties. Aboveground plant structures include stems, branches, leaves, shoots, flowers, and seeds, whereas the soil is dominated by the root system. These differing plant structures facilitate interactions between biotic communities that rarely come into direct physical contact with one another (Soler et al., 2008). In both the soil and aboveground 
compartments many organisms are associated with the plants, ranging from vertebrates and arthropods to micro-organisms. These organisms may have beneficial, neutral, or negative effects on plant fitness. Plants have evolved a range of strategies to optimize associations with beneficial organisms and/or to prevent or reduce the negative effect of attack from their antagonists. Roots may harbor many antagonists and therefore it is important that plants do not only defend themselves in the shoots but in their roots as well (Bezemer and van Dam, 2005; Van Dam, 2009). In a seminal paper, Ehrlich and Raven (1964) argued that plants and insects are involved in a sequential co-evolutionary arms race in which insect herbivores evolve strategies to deal with plant defences which are countered by new or stronger defences by the plant over evolutionary time. However, at the time their paper was written, the importance of this arms race was restricted to interactions between plants and insects in an aboveground framework. As we will explain here, this "arms race" can also involve interactions between roots and root herbivores as well as indirect interactions involving root and shoot tissues and herbivores feeding on plant structures in opposite compartments.

In this paper we discuss studies investigating the processes and underlying mechanisms that underpin multitrophic interactions with plants in the above- and belowground compartments (hereafter AG and BG). In particular, we broach a topic that has thus far received little attention in the empirical literature: factors generating and maintaining intraspecific variation in plant defense-related traits that are mediated through AG and BG trophic interactions. Plant defense traits often have a genetic basis. The effects of genetic variation in these plant traits on interactions with higher trophic level organisms have primarily been studied for AG plant parts (Crutsinger et al., 2006; Johnson, 2008; Newton et al., 2009a; Utsumi et al., 2011). In the last decade, complexity and ecological realism in experimental designs has increased. This also includes genetic variation in the interacting AG and BG compartments and its effect on interactions with associated organisms (Rasmann et al., 2009; Vandegehuchte et al., 2011). With this paper we make a plea for a more holistic approach with respect to genetic variation and AG-BG interactions. First we give a brief overview of the literature on plant-mediated multitrophic interactions in the AG and BG compartments and the hypotheses and underlying mechanisms that emerged from these studies. We then discuss the role of genetic variation in plant traits in shaping interactions with associated organisms. As an example, we give an overview of current knowledge on inter- and intraspecific AG$B G$ variation in plant defense traits and their consequences for interactions between insects and plant species in the large family Brassicaceae. We explore how different selection pressures at the species level may lead to the expression of variation in defense traits in roots and shoots using wild cabbage (Brassica oleracea) as our model species. We provide new data on root chemical defenses, show how this compares with better-studied AG defenses in this species, and highlight the importance of studying genetic variation in plant traits that play a role in AG and BG interactions with associated organisms in natural systems in order to explain the evolution and maintenance of variation among these traits.

\section{PLANT MEDIATED ABOVE- AND BELOWGROUND INTERACTIONS: PATTERNS AND HYPOTHESES}

Most studies involving plants and their defense traits in a bi- or multitrophic framework have focused on the AG compartment (reviewed by Price et al., 1980; Karban and Baldwin, 1997; Dicke, 1999; Harvey, 2005; Schoonhoven et al., 2005; Ode, 2006; Hopkins et al., 2009). These studies have provided a wealth of data showing that direct and indirect plant defenses can profoundly influence mechanisms governing species-level interactions and the structure of food webs up to (and perhaps even beyond) the fourth trophic level (Harvey et al., 2004, 2007; Bukovinszky et al., 2008). However, it is important to stress that plant-related traits, including defense, can also strongly influence biotic interactions BG (see reviews by Van der Putten et al., 2001; Van Dam et al., 2003; Bezemer and van Dam, 2005; Van Dam, 2009; Van Dam and Heil, 2011; Soler et al., 2012).

Given that plants may have to respond to variable stressors in both the AG and BG compartments, it is somewhat surprising that the importance and significance of interactions between these compartments has only emerged in the past 20 years or so. For example, studies by Gange and Brown (1989) and Masters and Brown (1992) showed that root herbivory by a root chewing insect was positively correlated with the pupal weight of a leaf mining insect. Masters (1995) found that leaf mining AG significantly decreased the performance of chafer larvae feeding $B G$, but at the same time root herbivory increased the pupal weight of the leaf miner. This positive influence of root feeding can also influence higher trophic levels. For instance, the abundance of a seed predator and two of its parasitoids were highest on thistle plants subjected to root herbivory (Masters et al., 2001).

It is now known that organisms in both compartments can indirectly influence each other through changes in the biomass, nutritional quality (primary metabolites) and chemical defense (secondary metabolites) of plants (Bezemer and van Dam, 2005; Van Ruijven et al., 2005). Recently, Kostenko et al. (2012) reported that in ragwort (Jacobaea vulgaris) herbivory by AG- and BGfeeding herbivores affects the soil fungal community, which in turn affects plant defense, biomass, and multitrophic interactions in ragwort plants in successive generations in different years. In many plant taxa secondary plant compounds are produced in the roots and then transported to AG plant structures (Karban and Baldwin, 1997). Besides defense compounds, levels of nutritional metabolites, such as amino acids and carbohydrates, are often also affected by damage (Bezemer and van Dam, 2005). The capacity of roots to absorb nutrients and the chemical composition of the soil are strongly affected by soil organisms. This affects the growth rate of plants, which is important in structuring plant communities and associated organisms (Van Dam and Heil, 2011).

Differences in physical characteristics of the AG and BG compartments may have profound effects on the spatial and temporal processes and scales that shape interactions between plants and associated organisms across several trophic levels. It is generally far easier for plant antagonists and mutualists to disperse in the AG than in the BG domain, since movement is clearly much more limited BG as a result of the simple physical difference 
between air and soil. For example, in the AG compartment, herbivores generally have easy access to plant parts, such as shoots and flowers, possibly resulting in intense short-term selection for defense-related (or in the case of pollinators, attractionbased) traits (Zangerl and Berenbaum, 1993; Majetic et al., 2009; Parachnowitsch etal., 2012). As a result of these differences in the scale of AG-BG interactions, plants may have evolved variable responses to organisms in each compartment based on time differentials in the temporal sequences (and/or accumulative effects) of these antagonists. This temporal differential may lead many plants to evolve strong AG defenses whereas they have evolved to "tolerate" their BG antagonists until some critical threshold is reached whereby a plant population is forced to relocate to a new habitat (the "above-ground selection, below-ground dispersal hypothesis"; Van der Putten et al., 2001; Bezemer et al., 2005). The release and perception of chemical cues, such as herbivore-induced plant volatiles (HIPVs), may also reflect differences between the AG and BG compartments. The rate and extent of transport of these cues are likely to be reduced BG. Furthermore concentrations of unspecialized and more specialized compounds may also differ between AG and BG plant tissues, and the dependency of chemical communication on water-soluble compounds is likely to be greater BG (Van der Putten et al., 2001).

Interactions between consumers in the AG and BG compartments have been very well studied in recent years (Wurst, 2010; Anderson et al., 2011; Soler et al., 2012, 2013). Many of these studies have focused on elucidating mechanisms involving AG and BG organisms sharing the same plant (Erb et al., 2008). These interactions may vary in terms of complexity and may involve organisms from several trophic levels and functional groups or feeding guilds. Moreover, different genotypes of one plant species can differ in their response to BG or AG organisms (Wurst et al., 2008; Harvey et al., 2011), and BG and AG organisms themselves can respond differentially to plant genotypes (Crutsinger et al., 2006; Johnson, 2008; Kabouw et al., 2011; Utsumi et al., 2011). The variable responses both in the plant and the herbivore make it difficult to predict the outcome of AG-BG plant-mediated interactions. For example, although plant genotype correlated positively with AG and BG invertebrate colonization, correlations between the AG and BG invertebrate groups themselves were negative, suggesting that the two groups selected plant genotype differentially (Vandegehuchte et al., 2011).

The importance of higher trophic levels on herbivore-plant interactions was recognized first by Price etal. (1980). Since AG-BG interactions may occur between organisms across several different feeding guilds and species, it is not surprising to find that the outcomes of these interactions may vary substantially from one association to another. Most AG-BG interaction experiments to date have focused on the effect of BG organisms on AG organisms, but there are also some studies that have looked at the effect of AG on BG (or both; for a more in-depth discussion, see reviews by Soler et al., 2012, 2013). Plant-mediated AG-BG interactions may be decidedly non-linear, whereby small scale interactions between a plant and one type of organism can affect entire AG and BG food webs and communities associated with that plant (Bardgett and Wardle, 2003; Wardle et al., 2004, 2005; De Deyn et al., 2007; Gerber et al., 2007; Heil, 2011).
Several hypotheses have been proposed on the underlying mechanisms determining plant-mediated AG-BG interactions. The stress response hypothesis states that the removal of root biomass by root feeding organisms causes a similar response as drought stress (Masters et al., 1993). This results in an accumulation of soluble nitrogen and carbon in aboveground plant parts, thus increasing the nutritional quality of the plant for AG herbivores (Masters and Brown, 1997). By contrast, the defense induction hypothesis posits that herbivores in the opposite compartments negatively influence each other through induction of toxic secondary plant compounds (Bezemer et al., 2003; Bezemer and van Dam, 2005). Because these compounds are often stored in the cells, phloem feeders will be less exposed to inducible toxic compounds, perhaps explaining why root feeders often negatively influence the performance of leaf chewers but not that of aphids. On the other hand, AG herbivores may negatively affect the growth and development of BG herbivores by reducing the availability of carbohydrates in the roots (Van der Putten et al., 2001). Using cotton plants, Bezemer et al. (2003) found no effect of previous feeding by a leaf chewing caterpillar Spodoptera exigua on the performance of root feeding Agriotes lineatus larvae. On the other hand, they found that root feeding by wireworms negatively affected the performance of $S$. exigua. Wurst et al. (2006) looked at the effect of two soil organisms on primary and secondary metabolites in cabbage and found that foliar concentrations of glucosinolates, secondary metabolites characteristic for brassicaceous plants, were affected by these organisms. Earthworms decreased the concentration of glucoiberin in the plant shoots and interactions between earthworms and root-knot nematodes in turn affected concentrations of glucoraphanin. This may have an influence on AG herbivores, since glucoiberin can act as a feeding and oviposition stimulant, providing support for the defense induction hypothesis (Wurst et al., 2006). Another study also found a negative impact of root feeding on the oviposition and feeding behavior of an aboveground herbivore (Anderson et al., 2011). More studies showed that root herbivory, through reduced plant quality, negatively affected the performance of AG herbivores, parasitoids and even hyperparasitoids (Van Dam et al., 2004a; Soler et al., 2005). AG herbivory by caterpillars of the large cabbage white butterfly, Pieris brassicae, negatively affected performance of a root feeding herbivore, the cabbage root fly, Delia radicum, and its endoparasitoid, Trybliographa rapae (Soler et al., 2007a). Infestation of pepper plants with whiteflies elicited a BG defense response, resulting in reduced infection when exposed to $A G$ and $B G$ bacterial pathogens, whilst positively affecting the association of plant roots with beneficial micro-organisms (Yang et al., 2011).

Not only are plant-mediated AG-BG interactions modified by the feeding activity of arthropods, but also by the composition of the soil micro-fauna. A meta-analysis of studies investigating the effect of mycorrhizal fungi on the performance of insect herbivores showed that the mycorrhizal status of host plants is often ignored in studies, despite the fact that mycorrhizal fungi can induce morphological, physiological, and biochemical changes and thus may influence plant quality for herbivores (Koricheva et al., 2009). In general, mycorrhizal fungi provide plants with nutrients and water and in return receive carbohydrates from the 
plant. The meta-analysis also revealed that phloem feeders benefited from mycorrhiza, whereas mesophyll feeders did not. The effect of dietary specialization in combination with feeding mode was only significant for the chewing and not for sucking sucking herbivores: specialist chewing herbivores performed better on plants colonized by mycorrhiza, whereas generalist chewing herbivores performed more poorly. In addition, mycorrhiza affected chewing herbivores negatively when these herbivores were feeding on the roots (Koricheva et al., 2009).

Bezemer et al. (2005) showed that the soil community composition can influence AG multitrophic interactions by affecting plant nutritional quality. Inoculation with nematodes negatively affected aphid offspring production, and aphid population size was lowest in microcosms with both nematodes and microorganism. The reverse was found for the aphid parasitoids which performed best in microcosms with both nematodes and microorganisms (Bezemer et al., 2005). These examples clearly illustrate that there are many different outcomes that may be generated by AG-BG interactions.

\section{DEFINING DIFFERENT TYPES OF GENETIC VARIATION}

Genetic variation can be studied at various levels of organization, from the expression of genes at the molecular level to variation in traits at the organismal level. Here, we have focused on genetic variation at the level of the individual plant. According to Whitham et al. (2003), in order to better understand interactions between species and communities, genetic variation should be divided in three classes: (1) genetic variation within single populations of the same species, (2) genetic variation between different populations of the same species, and (3) genetic variation among different species. Genetic variation is known to be expressed in many different plant traits, including morphology, phenology, primary and secondary chemistry. The expression of specific secondary metabolites is often taxonomically constrained (Schoonhoven et al., 2005). For example, different plant families are often characterized by their own classes of secondary metabolites, e.g., alkaloids in the Solaneceae, benzoxazinoids in the Poaceae, and glucosinolates in the Brassicaceae.

Intra-specific genetic variation in plant AG defense traits and its effects on the behavior and/or development of herbivores and their natural enemies in both lab and field studies has been well studied. In particular, much is known about this field of research in cultivated and wild plant species in the Brassicales, which includes cabbages, mustards, and related crops and their wild relatives. This includes Arabidopsis thaliana (Bidart-Bouzat and Kliebenstein, 2008; Wentzell and Kliebenstein, 2008), Brassica nigra (Lankau and Strauss, 2007, 2008), B. rapa (Pilson, 1996, 2000), Raphanus raphanistrum (Agrawal et al., 2002), and both wild (Harvey et al., 2007, 2011; Gols et al., 2008a,b; Newton et al., 2009a,b) and cultivated (Poelman et al., 2008; Kos et al., 2011) B. oleracea. These studies and others with different plant taxa have generated a wealth of mechanistic data showing the reciprocal effects of genetic variation in AG plant defense traits on consumers up the food chain, as well as both biotic and abiotic factors that may be driving this variation (Crutsinger et al., 2006; Johnson, 2008; Newton et al., 2009a; Utsumi et al., 2011).
Genetic variation is usually based on trade-offs involving the costs and benefits of retaining certain traits when metabolic resources are limiting (Stearns, 1992). For example, trade-offs may occur in resource allocation between defense traits and growth (e.g., competitive ability). This has been reported in a number of invasive plants when released from their co-evolved native enemies (e.g., pathogens and herbivores) in their new ranges. In this situation, plants quickly reallocate metabolic resources from defense to growth, meaning that they are able to out-compete native vegetation (Wolfe et al., 2004; Zangerl and Berenbaum, 2005). This rapid switch from defense to growth supports the predictions of the "enemy-release" and "evolution of increased competitive ability" hypotheses (Maron and Vila, 2001; Keane and Crawley, 2002; Colautti et al., 2004; Joshi and Vrieling, 2005). Within the group of plant defense traits, there are also numerous trade-offs. The different defense traits of plants may conflict because of their energy demand (Van der Putten et al., 2001).

Storing valuable resources in the roots can make a plant less attractive for AG herbivores, but it will make the roots more attractive to BG herbivores. Re-allocating resources from roots to shoots and leaves may affect resistance to AG herbivory, but also means limited capacity of the roots to establish/maintain mutualisms with BG microorganisms (Heil, 2011). Among populations, different plant traits can be selected for, depending on the local conditions. The resulting local adaptation means that individual plants have a higher fitness at their home site compared to other sites inhabited by the same species (Kalske et al., 2012). Trade-offs in local adaptation can be caused by limited resources, allocation costs, or ecological or genetic constraints (Kalske et al., 2012). Thus far, trade-offs in various defense related traits in plants in response to combined $\mathrm{AG}$ and $\mathrm{BG}$ biotic interactions has received little attention, and therefore is a fertile area for future research (but see Vandegehuchte et al., 2011). It is important to keep in mind that various plant traits are not necessarily costly to maintain or, conversely, only have weak (or no) effects on plant fitness, in which case it is unlikely that adaptation will occur.

\section{GENETIC VARIATION IN DEFENSE AND OTHER TRAITS IN PLANTS}

Evolution can only take place when natural selection acts on genetic variation in heritable traits that affect fitness (Whitham et al., 2003; Hughes et al., 2008). Without heritable phenotypic variation, there is no adaptive evolution possible. It is therefore important to determine what factors generate and maintain genetic variation within and between different populations (Siepielski and Benkman, 2009). Important sources for genetic variation in plants are introgression, mutation, and recombination at the gene level (Siepielski and Benkman, 2009), and also gene flow and genetic drift at the population level. The fact that there is heritable trait variation does not automatically mean that different levels of genetic diversity have predictable ecological consequences, because other factors (e.g., the environment) also play an important role (Hughes et al., 2008).

Genetic variation in plant defense traits is driven by a number of biotic and abiotic factors that may well be synergized (see discussion below with wild cabbage to get a better perspective). Much attention has been paid to trophic interactions between plants 
and their antagonists such as pathogens and herbivores, often in a co-evolutionary framework. Indeed, co-evolutionary theory underpins our understanding of intimate consumer-resource interactions in nature (Pimentel, 1961; Ehrlich and Raven, 1964; Rosenzweig, 1973; Abrams, 1986; Marrow and Cannings, 1993; Bonte et al., 2010; de la Peña etal., 2011). Many of the classical studies on co-evolutionary arms races and adaptive radiation have explored interactions between insect herbivores and their food plants (Ehrlich and Raven, 1964; Benson et al., 1975; Berenbaum and Zangerl, 1992; Hamrick and Godt, 1996; Pilson, 1996, 2000; Janz and Nylin, 1998; Lankau, 2007; Lankau and Strauss, 2007; Becerra et al., 2009; Cogni and Futuyma, 2009; Carmona etal., 2011; Bode and Kessler, 2012; Holeski et al., 2012; Bernhardsson et al., 2013). More recently it has been argued that selection for certain traits occurring in a pair-wise fashion are often generated at local or small landscape scales, and the term evolutionary "hotspots" has been invoked to describe this phenomenon (Thompson, 2005a). In this situation localized populations of closely interacting species interact intensively in small, often isolated patches and thus evolve unique traits that reflect adaptations to one another: one (the consumer) to exploit and one (the resource) to resist. Given that selection intensity can vary depending upon local conditions, evolutionary hotspots may be distributed over space and time as "geographic mosaics" (Thompson, 2005a). Thus far, however, discussion of selection pressures generated in hotspots has focused on the AG domain, with little effort to determine if and to what extent selection can occur from combined AG-BG interactions. To study this it is necessary to measure genetic variation in the expression of AG-BG plants traits and to determine if they are correlated (see e.g., Kaplan et al., 2008). Moreover, field studies are needed to identify and measure qualitative and quantitative differences in $A G$ and BG communities associated with a plant at different spatial and temporal scales. In addition, selection on certain plants may be characterized by diffuse selection (Strauss and Irwin, 2004; Vandegehuchte et al., 2011). Alternatively, herbivores may respond to variation in defense traits without exerting any selection pressures themselves.

As described above a plethora of studies have examined the biotic factors driving selection for AG defense traits in plants, and in particular allelochemistry (Coley et al., 1985; Schoonhoven et al., 2005). For example, Zangerl and Berenbaum explored whether herbivores can select for rapid increases in secondary metabolites (xanthotoxins) in plants, using wild parsnip and its main herbivore, the parsnip webworm, Depressaria pastinacella as a model system. This plant species harbors few herbivores in nature, aside from D. pastinacella, whose larvae attack seeds and thus may greatly affect plant fitness (Zangerl and Berenbaum, 1993). Wild parsnip has been introduced into various parts of the world where it has become an invasive pest in some areas (Berenbaum etal., 1986). In some regions where it has been introduced, webworms have also been released as a means of biological control, although in many habitats where the plant is established these herbivores are still absent. The main secondary metabolites in $P$. sativa are furanocoumarins, toxic compounds found primarily in species of the Apiaceae and Rutacea. Zangerl etal. (2008) showed that in areas where webworms are absent, parsnips rapidly responded by reducing investment in chemical defenses, suggesting that they are costly to maintain (see also Berenbaum and Zangerl, 2006). However, when webworms were introduced into regions where parsnips had been established for some years, the plants rapidly responded by reallocating metabolic resources to the production of furanocoumarins, showing that rapid evolutionary responses to chemical defenses are possible (Berenbaum and Zangerl, 1998).

The role of higher trophic levels, such as predators and parasitoids, in driving selection of plant-related traits has received less attention, although it has been amply demonstrated that natural enemies can significantly reduce herbivore abundance in agricultural landscapes (Luck et al., 1988; DeBach and Rosen, 1991). Cropping systems are often characterized by monocultures of plants whose direct chemical defenses have been greatly reduced as a result of artificial selection via domestication (Gols and Harvey, 2009). Natural systems are generally much more complex than agro-ecosystems chemically and structurally. How important trophic cascades involving insects are, has been the subject of debate (Hairston et al., 1960; Huntly, 1991; Schmitz et al., 2000). Evidence is coming to light that investment in costly plant secondary metabolites can be significantly influenced by the presence or absence of parasitoids, and that these effects generate phenotypic mosaics at the landscape-scale. Once again, the best studied system in which this area has been explored is the P. sativa-D. pastinacella association. Work by Berenbaum, Ode and colleagues has found that one parasitoid species, the encyrtid wasp Copidosoma sosares, devastates D. pastinacella populations where both species along with the food plant are native in western and central Europe (Ode et al., 2004; Berenbaum and Zangerl, 2006; Ode, 2006; Lampert et al., 2008). Where all three species are common in the native range, $P$. sativa plants are apparently less toxic than in areas of the invasive range where only the plant and herbivore have been established (Berenbaum and Zangerl, 2006). However, when plants and herbivores in the invasive range have been reunited with $C$. sosares, the plants quickly lower investment into the production of furanocoumarins, presumably because the parasitoids are again greatly reducing levels of herbivory (Berenbaum and Zangerl, 2006). Future studies comparing defense traits in populations of native and invasive plants in a multitrophic framework incorporating natural enemies offer much promise in better understanding rapid shifts in traits, such as from defense to growth. More importantly, future studies need to explore this combining AG and BG compartments, given what we already know about the importance of this linkage.

Where herbivores might select for high chemical defense levels, competition between plants might select for other plant traits although some of these may also involve phytotoxins (e.g., in the case of allelopathy). This is a complex matter, since plants compete not only with other plant species but also with conspecifics. For example, sinigrin produced by B. nigra is allelopathic and retards the germination and growth of wild oat and wild barley (Tawaha and Turk, 2003; Turk and Tawaha, 2003). Lankau and Strauss (2008) stated that, due to the costs of trait maintenance, a trait that improves interspecific competition will at the same time reduce intraspecific competition. Sinigrin is costly to produce and 
functions not only in competition with other plants but also as a defense compound against herbivores and pathogens.

In $B$. nigra there is a negative genetic trade-off between interand intraspecific competitive ability (Lankau and Strauss, 2008). When competing with different plant species, genotypes that produced high concentrations of sinigrin were strong competitors. However, in competition with conspecifics, these genotypes did poorly because there were no benefits to be gained from producing high concentrations of sinigrin (Lankau and Strauss, 2008; Lankau et al., 2011). While interspecific competition is primarily influenced by the allelopathic and antimycorrhizal effects of sinigrin, intraspecific competition is based on resource capture (Lankau and Strauss, 2007). Lankau and Strauss (2008) also found that the assembly of plant and herbivore species present in a community influence selection pressures acting on the production of sinigrin. Importantly, the identity of the competing plants affected selection for sinigrin production in the presence of herbivores more than the number of neighboring plants. Thus, the associated plant and herbivore community acts as an important and variable selection pressure on sinigrin in black mustard.

Johnson et al. (2008) studied the effect of plant genotype on intra-specific competition between evening primrose (Oenothera biennis) plants. This plant species exhibits heritable variation in above- and belowground growth and different genotypes responded differently to competition. Although evening primrose affected other plants through competition in the greenhouse, it was found that soil fertility had a much stronger effect and that in the field, there was no genotypic effect on neighboring plants. They concluded that in this case environmental variation was a stronger determinant of competition than plant genotype (Johnson et al., 2008).

Although this area has been little studied, we argue that interactions between plants and AG and BG organisms may influence the evolution of traits such as defense against herbivores, attraction of pollinators, as well as competition between plants for access to water, nutrients and light. The way these interactions are played out in natural communities can affect plant fitness. For example, Poveda et al. (2003) looked at the separate and combined effects of root and leaf herbivory on plant fitness in charlock mustard, Sinapis arvensis. Root herbivory marginally increased the flowering period and number of fruits produced when compared with combined root and leaf herbivory. It was also correlated with a higher per capita number of flower visits by pollinators (Poveda et al., 2003). These finding are in contrast with other studies where a negative effect of root herbivory on plant growth (Gange and Brown, 1989) or reproduction (Masters et al., 2001) was found, although in the Poveda etal. (2003) study this may have been caused by the low number of root herbivores per plant.

Barber et al. (2011) examined the effect of AG and BG herbivory on the performance of cucumber plants and found that, although root herbivory positively affected flower visitation by honey bees, root herbivory had a stronger negative effect on plant reproduction than leaf herbivory. Moreover, plant growth was reduced by both leaf and root feeding, whereas flower production was negatively affected by root herbivory resulting in less female flowers. Maron (1998) studied the effects of AG and BG insect herbivores on bush lupine and found that they had the potential to impose strong selection on the plant in several ways: via the suppression of $A G$ herbivores that increased seed production and via the suppression of BG herbivores that also increased seed production but which additionally decreased plant mortality. The results of these experiments shed some light on the complexity of AG-BG interactions and plant fitness and suggest that in terms of selection regimes the effects may not only be association-specific but also vary in different populations at the landscape scale.

Not only do herbivores exert selection pressures on plants, but it also works the other way around. Because plants and specialist herbivores are often involved in a co-evolutionary arms race, anti-herbivore defenses of plants may select for herbivore genotypes that are best able to deal with those defenses and vice versa (Kant et al., 2008). For example, spider mites dealing with jasmonic acid in tomato plants developed three different genotypes that differentiated in their induction of and resistance to jasmonic acid-induced defenses (Kant et al., 2008). Some populations of a perennial herb had associated herbivores that were locally adapted to their genotype, but in other populations the plants were adapted to the herbivores (Kalske et al., 2012). It remains to be determined at larger spatial (=geographical) scales if differences in combined AG-BG selection pressures can drive genetic variation in plant responses at the species and population level, as reflected in the measurement of different traits such as growth and defense. Moreover, how AG and BG plant responses in combination can drive reciprocal selection in herbivores and perhaps even their natural enemies is largely unknown (but see Bonte et al., 2010; Vandegehuchte et al., 2011). Although this infers the expression of some immensely complex processes that span several to many links, there is no reason that such effects do not occur in habitats where there are strong frequency-dependent AG and BG interactions.

\section{DEFENSE CHEMISTRY IN WILD CABBAGE, Brassica oleracea, AND RELATED SPECIES}

Plant species in the Brassicaceae are well studied with respect to (genetic) variation in secondary plant chemistry (Halkier and Gershenzon, 2006; Agerbirk and Olsen, 2012) and their interactions with AG and BG insect herbivores, but also with species in the third and even the fourth trophic level (Harvey et al., 2003; Soler et al., 2005, 2007b; Gols and Harvey, 2009; Hopkins et al., 2009). Secondary metabolites characteristic for plants in this family are the glucosinolates (hereafter GS). They are sulphur- and nitrogencontaining plant secondary metabolites that can be divided in three different classes based on their amino acid origin: aliphatic, indolyl and aromatic GS (Halkier and Gershenzon, 2006). When plant tissues are disrupted by for example insect feeding, myrosinase enzymes come into contact with the intact GS, and hydrolyze them into various hydrolysis products. Especially these GS breakdown products play a role in defenses against various attackers such as generalist insect herbivores and pathogens (Mithen, 2001). However, as specialist insect herbivores have evolved efficient mechanisms to excrete, detoxify or sequester GS (Bridges et al., 2002; Ratzka et al., 2002; Wittstock et al., 2004; Müller, 2009a), they may use GS and their breakdown products as stimuli to recognize host plants for oviposition and feeding (Renwick, 2002; Renwick et al., 2006; Bidart-Bouzat and Kliebenstein, 2008). Plant 
quality for specialist herbivores is determined by more general plant characteristics such as levels of primary metabolites and mechanical traits (Travers-Martin and Müller, 2008).

Various species of Brassicas differ in their GS profiles, both in AG and BG tissues (Figures 1 and 2). For example, the relative GS concentrations in AG and BG tissues differ dramatically, with root concentrations being much higher than shoot concentrations in Bunias orientalis, these being lower in B. nigra and similar in $S$. arvensis (Figure 1B). Usually, levels of GS are lower in BG than in AG tissues (Van Dam, 2009). Across species, variation in defense chemistry has been demonstrated to affect the performance of associated insects (Francis et al., 2001; Müller et al., 2002; Renwick, 2002; Harvey et al., 2003, 2010; Gols et al., 2008c). These dramatic differences in plant secondary chemistry at the species level may have implications for the interactions with other organisms in nature.

Although GS have been shown to play an important role in protecting plants against generalist insect herbivores (Blau et al., 1978; Gols et al., 2008a), other studies have shown that this is not always the case. For example sinalbin, the dominant GS in both $\mathrm{AB}$ and BG tissues in B. orientalis (Figure 1B) appears not to be effective against feeding by the generalist herbivore Mamestra brassicae (Harvey and Gols, 2011). Moreover, the high GS concentrations in BG tissues in this invasive species may play a role in its competitive abilities with other plant species or soil organisms that negatively affect growth and development of this plant and may explain its invasion success, but this needs to be tested empirically (Müller, 2009b). Remarkably, B. orientalis, which is readily accepted for oviposition, is a poor food plant for all studied specialist herbivores (Harvey et al., 2010). This result suggests that other chemicals in B. orientalis render these plants unsuitable for development of specialist herbivores.

Brassica oleracea is native to the coastlines, especially calcareous cliffs, of Western Europe and is considered the progenitor of cultivated cabbage (Mitchell and Richards, 1979). In the UK, the largest populations are on the south-west coast in the counties Cornwall, Devon, and Dorset (Wichmann et al., 2008). The distribution of the wild cabbage populations along the Dorset coast has been very constant over the past 70 years (Wichmann et al., 2008). These populations have also been the subject in a number of studies investigating the variation in GS metabolites, as well as the factors that maintain this variation considering that these populations grown often less than $15 \mathrm{~km}$ apart. The differences in GS profiles are most likely caused by divergent abiotic and biotic selection at the different sites (Mithen et al., 1995; Moyes et al., 2000; Moyes and Raybould, 2001; Newton et al., 2009a, 2010), although random processes such as founder effects and genetic drift may have played a role here as well.

Variation in the expression of GS is not only expressed across, but also within species. Population of wild cabbage differ considerably in their GS profiles (Figure 2) with concomitant consequences for the performance of insects in the second and third trophic level (Gols et al., 2008a; Harvey et al., 2011). Moreover, GS concentrations change in response to herbivory or simulated herbivory (see also Van Dam et al., 2004b) and population related differences in induction, although not found here (Figure 2B), have been reported for the wild cabbage populations when induced by a

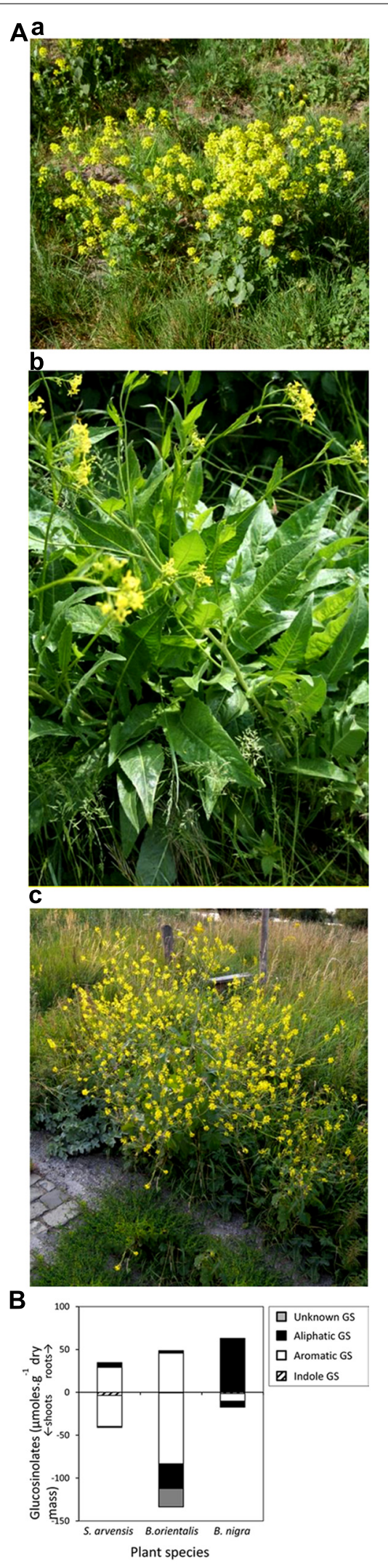

FIGURE 1 | Continued 


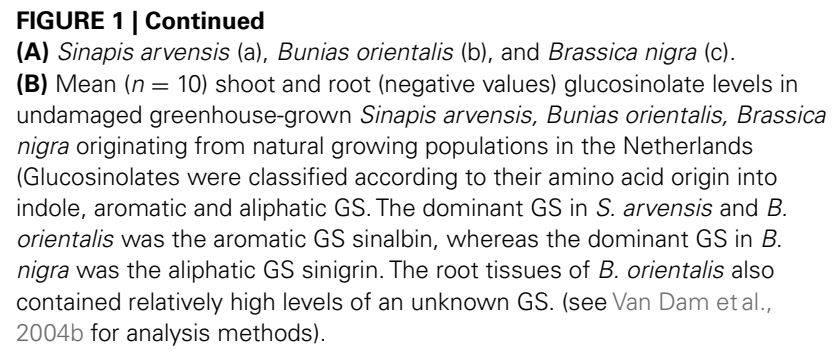

(A) Sinapis arvensis (a), Bunias orientalis (b), and Brassica nigra (c).

(B) Mean $(n=10)$ shoot and root (negative values) glucosinolate levels in undamaged greenhouse-grown Sinapis arvensis, Bunias orientalis, Brassica nigra originating from natural growing populations in the Netherlands (Glucosinolates were classified according to their amino acid origin into indole, aromatic and aliphatic GS. The dominant GS in $S$. arvensis and $B$. orientalis was the aromatic GS sinalbin, whereas the dominant GS in $B$. nigra was the aliphatic GS sinigrin. The root tissues of $B$. orientalis also contained relatively high levels of an unknown GS. (see Van Dam etal., 2004b for analysis methods)

different herbivore Pieris brassicae (Harvey et al., 2011). The variation in GS concentration appears to be more pronounced in AG than in BG tissues (Figure 2B). For example, indole GS dominate the profile in leaf tissues of the Kimmeridge (KIM) population, whereas leaves sampled from Winspit (WIN) plants contain high alkenyl GS concentrations. In the roots of the three populations all GS classes are represented and levels are relative little affected by induction compared to induction of foliar tissues.

Mithen et al. (1995) suggested that herbivores could act as an important selective force driving GS variation in the wild cabbage populations. However, Moyes et al. (2000) argued that for herbivores to act as a selection force, the herbivores need to select individual plants based on their GS profiles. They showed that there was a potential for host plant selection based on differences in the GS profiles of neighboring plants in the population on a small scale, but found no correlation between herbivore preference and GS profile except for one specialist herbivore species. They made the point that although laboratory experiments showed that GS influence the performance of herbivores, there was little evidence that this was also the case in nature (Moyes et al., 2000). In contrast, Newton et al. (2009a) reported significant differences in the response of herbivores to aliphatic GS, both within and between plant populations in the field. Based on their findings, they concluded that variation in GS can structure the associated herbivore community (i.e., herbivore mediated differential selection, Newton et al., 2009a). However, to demonstrate herbivore-mediated differential selection conclusively, further evidence is required showing that variable attacks by herbivores in the field have consequences for plant fitness (Newton et al., 2009a).

The populations along the Atlantic coast of England are known to be exposed to different abiotic conditions, despite their relative close proximity to each other. While some populations are located on high cliffs and thus are fully exposed to the prevailing wind, others are located in sheltered valleys. This may affect the colonization of plants by herbivores and their natural enemies, with populations on the cliffs experiencing low and population in the valleys experiencing high insect pressures. Soil characteristics such as clay and water content, soil texture, and nutrient levels have been reported to differ among the wild cabbage sites (Mithen et al., 1995; Wichmann etal., 2008). Little is known about the biotic selection pressures BG that may explain the relative lower variation in root GS chemistry of the wild cabbage populations. We currently investigate variation in associated soil communities at several of the wild cabbage sites in Dorset in order to reveal the degree of biotic $B G$ variation.
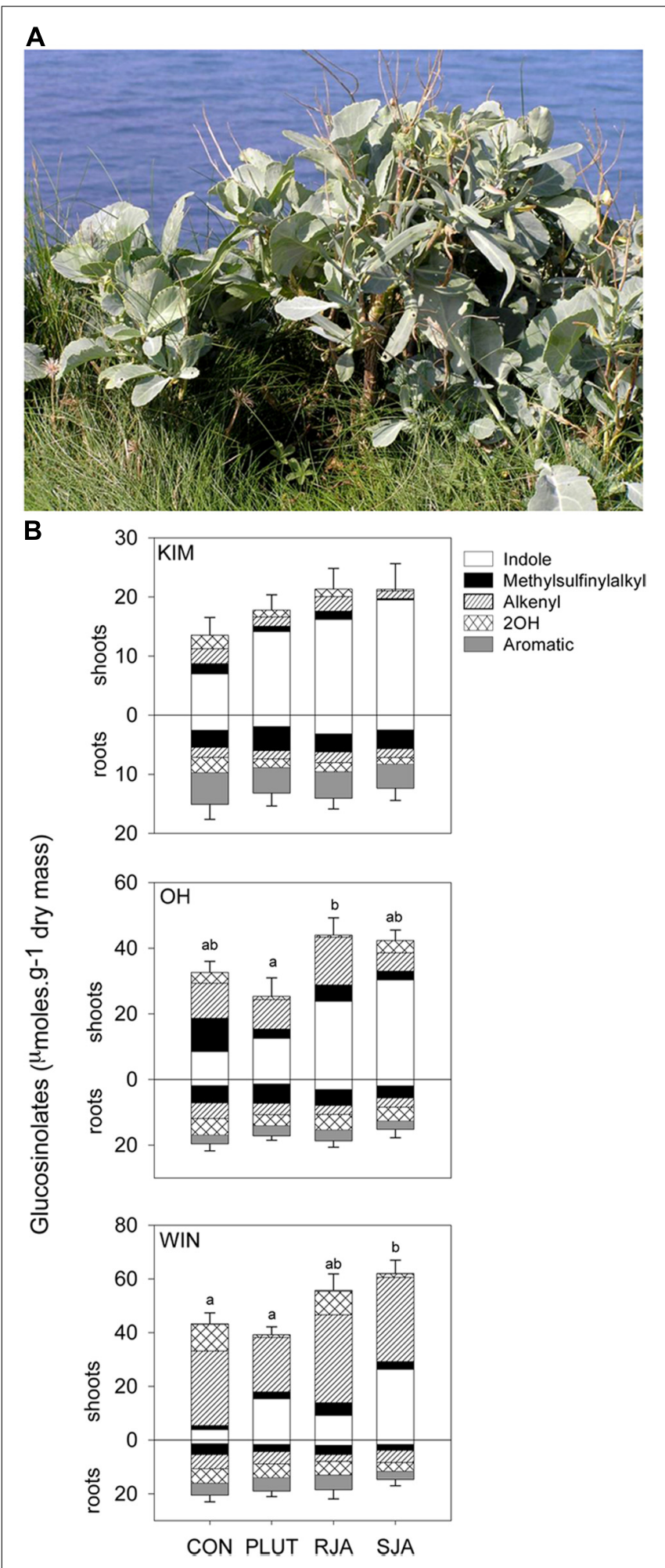

FIGURE 2 | (A) Brassica oleracea. (B) Shoot and root glucosinolate levels (mean + SE of mean total, $n=4$ or 5 ) of Brassica oleracea plants originating in Dorset, England from three wild populations located at sites called Kimmeridge (KIM), Old Harry $(\mathrm{OH})$, and Winspit (WIN), respectively. Glucosinolates were classified according to their amino acid origin into indole, aromatic and aliphatic GS. The latter group was further divided into (Continued) 


\section{FIGURE 2 | Continued}

methylsulfinyl, alkenyl, and hydroxyl $(=\mathrm{OH}) \mathrm{GS}$. The plants were either untreated controls (CON), induced with 9 second instar Plutella xylostella (PLUT) larvae divided over three leaves, induced with $500 \mu \mathrm{g}$ jasmonic acid either applied to the roots (RJA) or to the shoots (SJA). Jasmonic acid was used to simulate herbivory by chewing herbivores (Nan Dam et al., 2004b). Roots and shoot tissues were harvested for GS analysis 7 days after the induction treatments. Different letter over the bars indicate significant differences $(p<0.05)$ in total glucosinolate level between the bars within each panel (Tukey HSD multiple comparisons among means). Please note the difference in scaling of the Y-axes. Both population and induction treatment had a significant effect on total GS levels in wild $B$. oleracea (MANOVA, treatment $F_{6,82}=5.77, p<0.001$; population $F_{4,82}=18.7$, $p<0.001$ ). All classes of GS, as well as total GS concentrations, differed with population origin in both the roots and the shoots $(p<0.05$ for all analyses). In the shoots, indole GS $\left(F_{3,42}=23.9, p<0.001\right)$ increased in response to the three induction treatments. Aromatic GS were also affected by induction treatment $\left(F_{3,42}=3.34, p=0.03\right)$. Only WIN shoots contained small amounts of aromatic GS and these decreased with shoot induction, $P$. xylostella feeding and JA treatment, but increased with root JA application. In the roots, only indole GS responded significantly to induction treatment $\left(F_{3,42}=7.57, p<0.001\right)$; JA applied to the roots increased indole GS levels in these tissues.

The "Geographic Mosaic of Co-Evolution Theory" predicts that the intensity of selection pressure exerted by herbivores on plants may vary geographically (Thompson, 2005b). Local differences in selection pressure may thus result in populationrelated variation in the expression of certain traits. The ultimate question with respect to the wild cabbage populations is what processes maintain this high level of variation in secondary chemistry and potentially other traits and whether this variation is the consequence of strong selection pressures exerted locally. In addition, selection pressures may differ with respect to the AG and BG compartment. In other words, spatial heterogeneity in defense traits may be expressed differentially in AG and BG tissues as a result of differences in selection pressures in the two compartments. Moreover, the third trophic level as a selection force BG should be included as well (Price et al., 1980). In agricultural fields, cabbage root flies (Delia radicum) cause considerable damage to cabbage crops and they are also known to be attacked by various parasitoids species. Foraging behavior of parasitoids of Delia radicum has been reported to be affected by caterpillar feeding AG (Pierre et al., 2011). These results suggest the importance of a holistic approach of AG-BG multitrophic interactions.

\section{CONCLUSION AND FUTURE DIRECTIONS}

The study of AG-BG multitrophic interactions is now a major area of research in ecology. Over the past two decades a significant amount of empirical data has demonstrated the importance of AG-BG interactions in terms of mechanisms relating to the behavior and development of insects and other invertebrates, as well as effects on community structure and food webs. As the field continues to blossom, it is hoped that links between AG and BG compartments can be used to explain important applications in ecology, such as the production and delivery of important provisioning ecological services, e.g., the maintenance of soil fertility, nutrient cycling, pollination, and even regional climate control. There is little doubt that a more intensive multi-disciplinary approach to the study of AG and BG ecology will yield many insights into the functioning of ecological systems and their role in sustaining human civilization.

At present, however, there are still some significant gaps in our knowledge of important mechanisms and processes, such as in the spatio-temporal variation in AG-BG interactions and in how they may drive selection for different plant-related traits such as defense and competitive ability. Furthermore, we are only beginning to scratch the surface in our understanding and appreciation of the role played by natural enemies in generating variation in various plant traits. Given the potential importance of trade-offs between tolerance (growth) and defense in plants, the influence of natural enemies such as parasitoids in driving selection may be vastly underappreciated. If we incorporate natural enemies of plant antagonists in the soil, and then link these with three or even four trophic level interactions AG, there is a potential wealth of outcomes that remains to be explored. Moreover, given what we now know about evolutionary hotspots where selection is played out intensively, it would be interesting to search for these hotspots in a plant species within and between habitats, and to try and match phenotypes with strong AG, BG, and combined (AG and BG) selection regimes. Furthermore, given that plants can also potentially drive genetic variation in their associated consumers over several trophic levels and via multiple linkages, it would be interesting to explore how this may be played out combining AG and BG interactions.

We suggest several areas for future investigations:

(1) Studies working with different genotypes of wild plants and determining how these affect the behavior and performance of $A G$ and $B G$ insect herbivores and their natural enemies associated with them both independently and in combination;

(2) Analyzing various plant traits in roots and shoots in the same plant species both within and between populations along a geographical transect where abiotic and biotic selection pressures may vary. Furthermore, working to determine how differences in these traits are correlated with selection pressures from antagonists in the roots and shoots;

(3) Searching for geographical "hot-spots" in which selection for $\mathrm{AG}$ and $\mathrm{BG}$ responses are rigidly enforced and the interactions with the various consumers are identified;

(4) Comparing AG and BG interactions in geographically widespread plants both in the native and invasive ranges, and determining how release from their co-evolved natural enemies AG, BG (or both) may have led to a relaxation in selection for defense-related traits. Studies with invasive plants have generally ignored links between AG and BG trophic interactions, which may be a major omission in understanding why a small percentage of exotics become invasive pests.

In summary, we argue that the field of AG-BG multitrophic interactions needs to explore a wider range of biotic and abiotic selection pressures in explaining genetic variation in plant-related traits (and also reciprocally in their consumers up the food chain). In doing so it will be possible to develop a more thorough appreciation of the questions underpinning the immense variation in traits expressed in plants at various spatial scales. 


\section{ACKNOWLEDGMENTS}

The authors wish to thank various members of the Department of Terrestrial Ecology at the Netherlands Institute of Ecology for many valuable discussions over the years. Jeffrey A. Harvey and Moniek van Geem were financially supported by a Grant (No. 821006) from the Earth and Life Sciences Foundation (ALW), which is subsidized by the Netherlands Organization for Scientific Research (NWO). This is NIOO-KNAW publication 5539.

\section{REFERENCES}

Abrams, P. A. (1986). Adaptive responses of predators to prey and prey to predators: the failure of the arms race analogy. Evolution 40, 1229-1247. doi: $10.2307 / 2408950$

Agerbirk N., and Olsen C. E. (2012). Glucosinolate structures in evolution. Phytochemistry 77, 16-45. doi: 10.1016/j.phytochem.2012.02.005

Agrawal, A. A., Conner, J. K., Johnson, M. T. J., and Wallsgrove, R. (2002). Ecological genetics of an induced plant defense against herbivores: additive genetic variance and costs of phenotypic plasticity. Evolution 56, 2206-2213. doi: 10.1111/j.00143820.2002.tb00145.x

Anderson, P., Sadek, M. M., and Wäckers, F. L. (2011). Root herbivory affects oviposition and feeding behavior of a foliar herbivore. Behav. Ecol. 22, 1272-1277. doi: 10.1093/beheco/arr124

Barber, N. A., Adler, L. S., and Bernardo, H. L. (2011). Effects of above- and belowground herbivory on growth, pollination and reproduction in cucumber. Oecologia 165, 377-386. doi: 10.1007/s00442-010-1779-x

Bardgett, R. D., and Wardle, D. A. (2003). Herbivore-mediated linkages between aboveground and belowground communities. Ecology 84, 2258-2268. doi: 10.1890/02-0274

Becerra, J. X., Nogi, K., and Venable, D. L. (2009). Macroevolutionary chemical escalation in an ancient plant-herbivore arms race. Proc. Natl. Acad. Sci. U.S.A. 106, 18062-18066. doi: 10.1073/pnas.0904456106

Benson, W. W., Brown, K. S., and Gilbert, L. E. (1975). Coevolution of plants and herbivores: passion flower butterflies. Evolution 29, 659-680. doi: $10.2307 / 2407076$

Berenbaum, M. R., and Zangerl, A. R. (1992). Genetics of physiological and behavioral resistance to host furanocoumarins in the parsnip webworm. Evolution 46, 1373-1384. doi: 10.2307/2409943

Berenbaum, M. R., and Zangerl, A. R. (1998). Chemical phenotype matching between a plant and its insect herbivore. Proc. Natl. Acad. Sci. U.S.A. 95, 13743-13748. doi: 10.1073/pnas.95.23.13743

Berenbaum, M. R., and Zangerl, A. R. (2006). Parsnip webworms and host plants at home and abroad: trophic complexity in a geographic mosaic. Ecology 87, 3070-3081. doi: 10.1890/0012-9658(2006)87[3070:PWAHPA]2.0.CO;2

Berenbaum, M. R., Zangerl, A. R., and Nitao, J. K. (1986). Constraints on chemical coevolution-wild parsnip and the parsnip webworm. Evolution 40, 1215-1228. doi: 10.2307/2408949

Bernhardsson, C., Robinson, K. M., Abreu, I. N., Jansson, S., Albrectsen, B. R., and Ingvarsson, P. K. (2013). Geographic structure in metabolome and herbivore community co-occurs with genetic structure in plant defence genes. Ecol. Lett. 16, 791-798. doi: 10.1111/ele.12114

Bezemer, T. M., De Deyn, G. B., Bossing, T. M., van Dam, N. M., Harvey, J. A., and van der Putten, W. H. (2005). Soil community composition drives aboveground plantherbivore-parasitoid interactions. Ecol. Lett. 8, 652-661. doi: 10.1111/j.14610248.2005.00762.x

Bezemer, T. M., and van Dam, N. M. (2005). Linking aboveground and belowground interactions via induced plant defenses. Trends Ecol. Evol. 20, 617-624. doi: 10.1016/j.tree.2005.08.006

Bezemer, T. M., Wagenaar, R., van Dam, N. M., and Wackers, F. L. (2003). Interactions between above- and belowground insect herbivores as mediated by the plant defense system. Oikos 101, 555-562. doi: 10.1034/j.1600-0706.2003.12424.x

Bidart-Bouzat, M. G., and Kliebenstein, D. J. (2008). Differential levels of insect herbivory in the field associated with genotypic variation in glucosinolates in Arabidopsis thaliana. J. Chem. Ecol. 34, 1026-1037. doi: 10.1007/s10886-0089498-Z

Blau, P. A., Feeny, P., Contardo, L., and Robson, D. S. (1978). Allylglucosinolate and herbivorous caterpillars: a contrast in toxicity and tolerance. Science 200, 1296-1298. doi: 10.1126/science.200.4347.1296
Bode, R. F., and Kessler, A. (2012). Herbivore pressure on goldenrod (Solidago altissima L. Asteraceae): its effect on herbivore resistance and vegetative production. J. Ecol. 100, 795-801. doi: 10.1111/j.1365-2745.2012. 01958.x

Bonte, D., de Roissart, A., Vandegehuchte, M. L., Ballhorn, D. J., Van Leeuwen, T., and de la Peña E. (2010). Local adaptation of aboveground herbivores towards plant phenotypes induced by soil biota. PLOS ONE 5:e11174. doi: 10.1371/journal.pone.0011174

Bridges, M., Jones, A. M. E., Bones, A. M., Hodgson, C., Cole, R., Bartlet, E., et al. (2002). Spatial organization of the glucosinolate-myrosinase system in Brassica specialist aphids is similar to that of the host plant. Proc. R. Soc. Lond. B Biol. Sci. 269, 187-191. doi: 10.1098/rspb.2001.1861

Bukovinszky, T., van Veen, F. J. F., Jongema, Y., and Dicke, M. (2008). Direct and indirect effects of resource quality on food web structure. Science 319, 804-807. doi: 10.1126/science. 1148310

Carmona, D., Lajeunesse, M. J., and Johnson, M. T. J. (2011). Plant traits that predict resistance to herbivores. Funct. Ecol. 25, 358-367. doi: 10.1111/j.13652435.2010.01794.x

Cogni, R., and Futuyma, D. J. (2009). Local adaptation in a plant herbivore interaction depends on the spatial scale. Biol. J. Linn. Soc. 97, 494-502. doi: 10.1111/j.1095-8312.2009.01234.x

Colautti, R. I., Ricciardi, A., Grigorovich, I. A., and MacIsaac, H. J. (2004). Is invasion success explained by the enemy release hypothesis? Ecol. Lett. 7, 721-733. doi: 10.1111/j.1461-0248.2004.00616.x

Coley, P. D., Bryant, J. P., and Chapin, F. S. (1985). Resource availability and plant antiherbivore defense. Science 230, 895-899. doi: 10.1126/science.230.4728.895

Crutsinger, G. M., Collins, M. D., Fordyce, J. A., Gompert, Z., Nice, C. C., and Sanders, N. J. (2006). Plant genotypic diversity predicts community structure and governs an ecosystem process. Science 313, 966-968. doi: 10.1126/science. 1128326

DeBach, P., and Rosen, D. (1991). Biological Control by Natural Enemies. Cambridge: Cambridge University Press.

De Deyn, G. B., van Ruijven, J., Raaijmakers, C. E., de Ruiter, P. C., and van der Putten, W. H. (2007). Above- and belowground insect herbivores differentially affect soil nematode communities in species-rich plant communities. Oikos 116, 923-970. doi: 10.1111/j.0030-1299.2007.15761.x

de la Peña, E., D'Hondt, B., and Bonte, D. (2011). Landscape structure, dispersal and the evolution of antagonistic plant-herbivore interactions. Ecography 34, 480-487. doi: 10.1111/j.1600-0587.2010.06524.x

Dicke, M. (1999). Are herbivore-induced plant volatiles reliable indicators of herbivore identity to foraging carnivorous arthropods? Entomol. Exp. Appl. 91, 131-142. doi: 10.1046/j.1570-7458.1999.00475.x

Ehrlich, P. R., and Raven, P. H. (1964). Butterflies and plants - a study in coevolution. Evolution 18, 586-608. doi: 10.2307/2406212

Erb, M., Ton, J., Degenhardt, J., and Turlings, T. C. J. (2008). Interactions between arthropod-induced aboveground and belowground defenses in plants. Plant Physiol. 146, 867-874. doi: 10.1104/pp.107.112169

Francis, F., Lognay, G., Wathelet, J. P., and Haubruge, E. (2001). Effects of allelochemicals from first (Brassicaceae) and second (Myzus persicae and Brevicoryne brassicae) trophic levels on Adalia bipunctata. J. Chem. Ecol. 27, 243-256. doi: 10.1023/A:1005672220342

Gange, A. C., and Brown, V. K. (1989). Effects of root herbivory by an insect on a foliar feeding species, mediated through changes in the host plant. Oecologia 81, 38-42. doi: 10.1007/BF00377007

Gerber, E., Hinz, H. L., and Blossey, B. (2007). Interactions of specialist root and shoot herbivores of Alliaria petiolate and their impact on plant performance and reproduction. Ecol. Entomol.32, 357-365. doi: 10.1111/j.1365-2311.2007.00875.x Gols, R., and Harvey J. A. (2009). Plant-mediated effects in the Brassicaceae on the performance and behaviour of parasitoids. Phytochem. Rev. 8, 187-206. doi: 10.1007/s11101-008-9104-6

Gols, R., Wagenaar, R., Bukovinszky, T., van Dam, N. M., Dicke, M., Bullock, J. M., et al. (2008a). Genetic variation in defense chemistry in wild cabbages affect herbivores and their endoparasitoids. Ecology 89, 1616-1626. doi: 10.1890/070873.1

Gols, R., Witjes, L. M. A., van Loon, J. J. A., Posthumus, M. A., Dike, M., and Harvey, J. A. (2008b). The effect of direct and indirect defenses in two wild Brassicaceous plant species on a specialist herbivore and is gregarious endoparasitoid. Entomol. Exp. Appl. 128, 99-108. doi: 10.1111/j.1570-7458.2008.00681.x 
Gols, R., Bukovinszky, T., van Dam, N. M., Dicke, M., Bullock, J. M., and Harvey, J. A. (2008c). Performance of generalist and specialist herbivores and their endoparasitoids differs on cultivated and wild Brassica populations. J. Chem. Ecol. 34, 132-143. doi: 10.1007/s10886-008-9429-Z

Hairston, N. G., Smith, F. E., and Slobodkin, L. B. (1960). Community structure, population control, and competition. Am. Nat. 94, 421-425. doi: 10.1086/282146

Halkier, B. A., and Gershenzon, J. (2006). Biology and biochemistry of glucosinolates. Annu. Rev. Plant Biol. 57, 303-333. doi: 10.1146/annurev.arplant. 57.032905.105228

Hamrick, J. L., and Godt, M. J. W. (1996). Effects of life history traits on genetic diversity in plant species. Philos. Trans. R. Soc. Lond. B Biol. Sci. 351, 1291-1298. doi: 10.1098/rstb.1996.0112

Harvey, J. A. (2005). Factors affecting the evolution of development strategies in parasitoid wasps: the importance of functional constraints and incorporating complexity. Entomol. Exp. Appl. 117, 1-13. doi: 10.1111/j.1570-7458.2005.00348.x

Harvey, J. A., Biere, A., Fortuna, T., Vet, L. E. M., Engelkes, T., Morrien, E., et al. (2010). Ecological fits, mis-fits and lotteries involving insect herbivores on the invasive plant, Bunias orientalis. Biol. Invasions 12, 3045-3059. doi: 10.1007/s10530-010-9696-9

Harvey, J. A., and Gols, R. (2011). Development of Mamestra brassicae and its solitary endoparasitoid Microplitis mediator on two populations of the invasive weed Bunias orientalis. Popul. Ecol. 53, 587-596. doi: 10.1007/s10144-011-0267-4

Harvey, J. A., van Dam, N. M., and Gols, R. (2003). Interactions over four trophic levels: foodplant quality affects development of a hyperparasitoid as mediated through a herbivore and its primary parasitoid. J. Anim. Ecol. 72, 520-531. doi: 10.1046/j.1365-2656.2003.00722.x

Harvey, J. A., van Dam, N. M., Raaijmakers, C. E., Bullock, J. M., and Gols, R. (2011). Tri-trophic effects of inter- and intra-population variation in defence chemistry of wild cabbage (Brassica oleracea). Oecologia 166: 421-431. doi: 10.1007/s00442010-1861-4

Harvey, J. A., van Dam, N. M., Witjes, L. M. A., Solerro, R., and Gols, R. (2007). Effects of dietary nicotine on the development of an insect herbivore, its parasitoid and secondary hyperparasitoid over four trophic levels. Ecol. Entomol. 32, 15-23. doi: 10.1111/j.1365-2311.2006.00838.x

Harvey, J. A., Witjes, L. M. A., and Wagenaar, R. (2004). Development of hyperparasitoid wasp Lysibia nana (Hymenoptera: Ichneumonidae) in a multitrophic framework. Environ. Entomol. 33, 1488-1496. doi: 10.1603/0046-225X-33.5.1488

Heil, M. (2011). Plant-mediated interactions between above- and belowground communities at multiple trophic levels. J. Ecol. 99, 3-6. doi: 10.1111/j.13652745.2010.01773.x

Holeski, L. M., Hillstrom, M. L., Whitham, T. G., and Lindroth, R. L. (2012). Relative importance of genetic, ontogenetic, induction, and seasonal variation in producing a multivariate defense phenotype in a foundation tree species. Oecologia 170, 695-707. doi: 10.1007/s00442-012-2344-6

Hopkins, R. J., van Dam, N. M., and van Loon, J. J. A. (2009). Role of glucosinolates in insect-plant relationships and multitrophic interactions. Annu. Rev. Entomol. 54, 57-83. doi: 10.1146/annurev.ento.54.110807.090623

Hughes, A. R., Inouye, B. D., Johnson, M. T. J., Underwood, N., and Vellend, M. (2008). Ecological consequences of genetic diversity. Ecol. Lett. 11, 609-623. doi: 10.1111/j.1461-0248.2008.01179.x

Huntly, N. (1991). Herbivores and the dynamics of communities and ecosystems. Annu. Rev. Ecol. Syst. 22, 477-503. doi: 10.1146/annurev.es.22.110191.002401

Janz, N., and S. Nylin, S. (1998). Butterflies and plants: a phylogenetic study. Evolution 52, 486-502. doi: 10.2307/2411084

Johnson, M. T. J. (2008). Bottom-up effects of plant genotype on aphids, ants, and predators. Ecology 89, 145-154. doi: 10.1890/07-0395.1

Johnson, M. T. J., Dinnage, R., Zhou, A. Y., and Hunter, M. D. (2008). Environmental variation has stronger effects than genotype on competition among plant species. J. Ecol. 96, 947-955. doi: 10.1111/j.1365-2745.2008.01410.x

Joshi, J., and Vrieling, K. (2005). The enemy release and EICA hypothesis revisited: incorporating the fundamental difference between specialist and generalist herbivores. Ecol. Lett. 8, 704-714. doi: 10.1111/j.1461-0248.2005.00769.x

Kabouw, P., Kos, M., Kleine, S., Vockenhuber, E. A., van Loon, J. J. A., van der Putten, W. H., et al. (2011). Effects of soil organisms on aboveground multitrophic interactions are consistent between plant genotypes mediating the interaction. Entomol. Exp. Appl. 139, 197-206. doi: 10.1111/j.1570-7458.2011.01123.x

Kalske, A., Muola, A., Laukkanen, L., Mutikainen, P., and Leimu, R. (2012). Variation and constraints of local adaptation of a long-lived plant, its pollinators and specialist herbivores. J. Ecol. 100, 1359-1372. doi: 10.1111/j.1365-2745.2012. 02008.x

Kant, M. R., Sabelis, M. W., Haring, M. A., and Schuurink, R. C. (2008). Intraspecific variation in a generalist herbivore accounts for differential induction and impact of host plant defences. Proc. R. Soc. Lond. B Biol. Sci. 275, 443-452. doi: 10.1098/rspb.2007.1277

Kaplan, I., Halitschke, R., Kessler, A., Rehill, B. J., Sardanelli, S., and Denno, R. F. (2008). Physiological integration of roots and shoots in plant defense strategies links above- and belowground herbivory. Ecol. Lett. 11, 841-851. doi: 10.1111/j.1461-0248.2008.01200.x

Karban, R., and Baldwin, I. T. (1997). Induced Responses to Herbivory. Chicago: University of Chicago Press. doi: 10.7208/chicago/9780226424972.001.0001

Keane, R. M., and Crawley, M. J. (2002). Exotic plant invasions and the enemy release hypothesis. Trends Ecol. Evol. 17, 164-170. doi: 10.1016/S0169-5347(02)02499-0

Koricheva, J., Gange, A. C., and Jones, T. (2009). Effects of Mycorrhizal fungi on insect herbivores: a meta-analysis. Ecology 90, 2088-2097. doi: 10.1890/08-1555.1

Kos, M., Kabouw, P., Noordam, R., Hendriks, K., Vet, L. E. M., van Loon, J. J. A., et al. (2011). Prey-mediated effects of glucosinolates on aphid predators. Ecol. Entomol. 36, 377-388. doi: 10.1111/j.1365-2311.2011.01282.x

Kostenko, O., Van de Voorde, T. F. J., Mulder, P. P. J., Van der Putten, W. H., and Bezemer, T. M. (2012). Legacy effects of aboveground-belowground interactions. Ecol. Lett. 15, 813-821. doi: 10.1111/j.1461-0248.2012.01801.x

Lampert, E. C., Zangerl, A. R., Berenbaum, M. R., and Ode, P. J. (2008). Tritrophic effects of xanthotoxin on the polyembryonic parasitoid Copidosoma sosares (Hymenoptera: Encyrtidae). J. Chem. Ecol. 34, 783-790. doi: 10.1007/s10886-008-9481-8

Lankau, R. A. (2007). Specialist and generalist herbivores exert opposing selection on a chemical defense. New Phytol. 175, 176-184. doi: 10.1111/j.14698137.2007.02090.x

Lankau, R. A., and Strauss, S. Y. (2007). Mutual feedbacks maintain both genetic and species diversity in a plant community. Science 317, 1561-1563. doi: 10.1126/science. 1147455

Lankau, R. A., and Strauss, S. Y. (2008). Community complexity drives patterns of natural selection on a chemical defense of Brassica nigra. Am. Nat. 171, 150-161. doi: 10.1086/524959

Lankau, R. A., Wheeler, E., Bennet, A. E., and Strauss, S. Y. (2011). Plantsoil feedbacks contribute to an intransitive competitive network that promotes both genetic and species diversity. J. Ecol. 99, 176-185. doi: 10.1111/j.13652745.2010.01736.x

Luck, R. F., Shepard, B. M., and Kenmore, P. E. (1988). Experimental methods for evaluating arthropod natural enemies. Annu. Rev. Entomol. 33, 367-391. doi: 10.1146/annurev.en.33.010188.002055

Majetic, C. J., Raguso, R. A., and Ashman, T.-L. (2009). The sweet smell of success: floral scent affects pollinator attraction and seed fitness in Hesperis matronalis. Funct. Ecol. 23, 480-487. doi: 10.1111/j.1365-2435.2008.01517.x

Maron, J. L. (1998). Insect herbivory above- and belowground: individual and joint effects on plant fitness. Ecology 79, 1281-1293. doi: 10.1890/00129658(1998)079[1281:IHAABI]2.0.CO;2

Maron, J. L., and Vila, M. (2001). When do herbivores affect plant invasion? Evidence for the natural enemies and biotic resistance hypotheses. Oikos 95, 361-373. doi: 10.1034/j.1600-0706.2001.950301.x

Marrow, P., and Cannings, C. (1993). Evolutionary instability in predator-prey systems. J. Theor. Biol. 160, 135-150. doi: 10.1006/jtbi.1993.1008

Masters, G. J. (1995). The effect of herbivore density on host plant mediated interactions between two insects. Ecol. Res. 10, 125-133. doi: 10.1007/BF023 47934

Masters, G. J., and Brown, V. K. (1992). Plant-mediated interactions between two spatially separated insects. Funct. Ecol. 6, 175-179. doi: 10.2307/2389752

Masters, G. J., and Brown, V. K. (1997). "Host-plant mediated interactions between spatially separated herbivores: effects on community structure," in Multritrophic Interactions in Terrestrial Systems, eds A. C. Gange and V. K. Brown (Oxford: Blackwell), 217-237.

Masters, G. J., Brown, V. K., and Gange, A. C. (1993). Plant mediated interactions between aboveground and belowground insect herbivores. Oikos 66, 148-151. doi: $10.2307 / 3545209$

Masters, G. J., Jones, T. H., and Rogers, M. (2001). Host-plant mediated effects of root herbivory on insect seed predators and their parasitoids. Oecologia 127, 246-250. doi: 10.1007/s004420000569 
Mitchell, N. D., and Richards, A. J. (1979). Biological flora of the British Isles: Brassica oleracea L. ssp. oleracea (B. sylvestris (L.) Miller). J. Ecol. 67, 1087-1096. doi: $10.2307 / 2259229$

Mithen, R., Raybould, A. F., and Giamoustaris, A. (1995). Divergent selection for secondary metabolites between wild populations of Brassica oleracea and its implications for plant-herbivore interactions. Heredity 75, 472-484. doi: 10.1038/hdy.1995.164

Mithen, R. (2001). Glucosinolates - biochemistry, genetics and biological activity. Plant Growth Regul. 34, 91-103. doi: 10.1023/A:1013330819778

Moyes, C. L., Collin, H. A., Britton, G., and Raybould, A. F. (2000). Glucosinolates and differential herbivory in wild populations of Brassica oleracea. J. Chem. Ecol. 26, 2625-2641. doi: 10.1023/A:1005549115751

Moyes, C. L., and Raybould, A. F. (2001). The role of spatial scale and intraspecific variation in secondary chemistry in host-plant location by Ceutorhynchus assimilis (Coleoptera: Curculionidae). Proc. R. Soc. Lond. B Biol. Sci. 268, 1567-1573. doi: 10.1098/rspb.2001.1685

Müller, C. (2009a). Interactions between glucosinolate- and myrosinase-containing plants and the sawfly Athalia rosae. Phytochem. Rev. 8, 121-134. doi: 10.1007/s11101-008-9115-3

Müller, C. (2009b). Role of glucosinolates in plant invasiveness. Phytochem. Rev. 8 , 227-242. doi: 10.1007/s11101-008-9116-2

Müller, C., Boevé, J. L., and Brakefield, P. (2002). Host plant derived feeding deterrence towards ants in the turnip sawfly Athalia rosae. Entomol. Exp. Appl. 104 153-157. doi: 10.1046/j.1570-7458.2002.01002.x

Newton, E. L., Bullock, J. M., and Hodgson, D. J. (2009a). Glucosinolate polymorphism in wild cabbage (Brassica oleracea) influences the structure of herbivore communities. Oecologia 160, 63-76. doi: 10.1007/s00442-009-1281-5

Newton, E. L., Bullock, J. M., and Hogdson, D. J. (2009b). Bottom-up effects of glucosinolate variation on aphid colony dynamics in wild cabbage populations. Ecol. Entomol. 34, 614-623. doi: 10.1111/j.1365-2311.2009.01111.x

Newton, E., Bullock, J. M., and Hodgson, D. (2010). Temporal consistency in herbivore responses to glucosinolates polymorphism in populations of wild cabbage (Brassica oleracea). Oecologia 164, 689-699. doi: 10.1007/s00442-010-1702-5

Ode, P. J. (2006). Plant chemistry and natural enemy fitness: effects on herbivore and natural enemy interactions. Annu. Rev. Entomol. 51, 163-185. doi: 10.1146/annurev.ento.51.110104.151110

Ode, P. J., Berenbaum, M. R., Zangerl, A. R., and Hardy, I. C. W. (2004). Host plant, host plant chemistry and the polyembryonic parasitoid Copidosoma sosares: indirect effects in a tritrophic interaction. Oikos 104, 388-400. doi: 10.1111/j.0030-1299.2004.12323.x

Parachnowitsch, A. L., Raguso, R. A., and Kessler, A. (2012). Phenotypic selection to increase floral scent emission, but not flower size or colour in beepollinated Penstemon digitalis. New Phytol. 195, 667-675. doi: 10.1111/j.14698137.2012.04188.x

Pierre, P. S., Dugravot, S., Ferry, A., Soler, R., van Dam, N. M., and Cortesero, A. M. (2011). Aboveground herbivory affects indirect defences of brassicaceous plants against the root feeder Delia radicum Linnaeus: laboratory and field evidence. Ecol. Entomol. 36, 326-334. doi: 10.1111/j.1365-2311.2011.01276.x

Pilson, D. (1996). Two herbivores and constraints on selection for resistance in Brassica rapa. Evolution 3, 1492-1500. doi: 10.2307/2410886

Pilson, D. (2000). The evolution of plant response to herbivory: simultaneously considering resistance and tolerance in Brassica rapa. Evol. Ecol. 14, 457-489. doi: 10.1023/A:1010953714344

Pimentel, D. (1961). Animal population regulation by the genetic feedback mechanism. Am. Nat. 95, 65-79. doi: 10.1086/282160

Poelman, E. H., Galiart, R. J. F. H., Raaijmakers, C. E., van Loon, J. J. A., and van Dam, N. M. (2008). Performance of specialist and generalist herbivores feeding on cabbage cultivars is not explained by glucosinolate profiles. Entomol. Exp. Appl. 127, 218-228. doi: 10.1111/j.1570-7458.2008.00700.x

Poveda, K., Stefan-Dewenter, I., Scheu, S., and Tscharntke, T. (2003). Effects of below- and aboveground herbivores on plant growth, flower visitation and seed set. Oecologia 135, 601-605. doi:10.1007/s00442-003-1228-1

Price, P. W., Bouton, C. E., Gross, P., McPheron, B. A., Thompson, J. N., and Weis, A. E. (1980). Interactions among three trophic levels: influence of plants on interactions between insect herbivores and natural enemies. Annu. Rev. Ecol. Syst. 11, 41-65. doi: 10.1146/annurev.es.11.110180.000353

Rasmann, S., Agrawal, A. A., Cook, S. C., and Erwin, A. C. (2009). Cardenolides, induced responses, and interactions between above- and belowground herbivores0 of milkweed (Asclepias spp.). Ecology 90, 2393-2404. doi: 10.1890/081895.1

Ratzka, A., Vogel, H., Kliebenstein, D. J., Mitchell-Olds, T., and Kroymann, J. (2002). Disarming the mustard oil bomb. Proc. Natl. Acad. Sci. U.S.A. 99, 11223-11228. doi: 10.1073/pnas.172112899

Renwick, J. A. A. (2002). The chemical world of crucivores: lures, treats and traps. Entomol. Exp. Appl. 104, 35-42. doi: 10.1046/j.1570-7458.2002.00988.x

Renwick, J. A. A., Haribal, M., Gouinguene, S., and Stadler, E. (2006). Isothiocyanates stimulating oviposition by the diamondback moth, Plutella xylostella. J. Chem. Ecol. 32, 755-766. doi: 10.1007/s10886-006-9036-9

Rosenzweig, M. L. (1973). Evolution of the predator isocline. Evolution 27, 84-94. doi: $10.2307 / 2407121$

Schmitz, O. J., Hambäck, P. A., and Beckerman, A. P. (2000). Trophic cascades in terrestrial systems: a review of the effects of carnivore removal on plants. Am. Nat. 155, 141-153. doi: 10.1086/303311

Schoonhoven, L. M., van Loon, J. J. A., and Dicke, M. (2005). Insect-Plant Biology. Oxford: Oxford University Press.

Siepielski, A. M., and Benkman, C. W. (2009). Conflicting selection from an antagonist and a mutualist enhances phenotypic variation in a plant. Evolution 64, 1120-1128. doi: 10.1111/j.1558-5646.2009.00867.x

Soler, R., Bezemer, T. M., van der Putten, W. H., Vet, L. E. M., and Harvey, J. A. (2005). Root herbivore effects on above-ground herbivore, parasitoid and hyperparasitoid performance via changes in plant quality. J. Anim. Ecol. 74, 1121-1130. doi: 10.1111/j.1365-2656.2005.01006.x

Soler, R., Bezemer, T. M., Cortesero, A. M., van der Putten, W. H., Vet, L. E. M., and Harvey, J. A. (2007a). Impact of foliar herbivory on the development of a rootfeeding insect and its parasitoid. Oecologia 152, 257-264. doi: 10.1007/s00442006-0649-z

Soler, R., Harvey, J. A., Kamp, A. F. D., Vet, L. E. M., van der Putten, W. H., van Dam, N. M., et al. (2007b). Root herbivores influence the behaviour of an aboveground parasitoid through changes in plant-volatile signals. Oikos 116, 367-376. doi: 10.1111/j.0030-1299.2007.15501.x

Soler, R., Bezemer, T. M., and Harvey, J. A. (2013). "Chemical ecology of insect parasitoids in a multitrophic above- and belowground context" in Chemical Ecology of Insect Parasitoids, eds E. Wajnberg and S. Colazza (Oxford: Wiley-Blackwell), 64-85.

Soler, R., Harvey, J. A., Bezemer, T. M., and Stuefer, J. F. (2008). Plants as green phones. Novel insights into plant-mediated communication between belowand aboveground insect. Plant Signal. Behav. 3, 519-520. doi: 10.4161/psb.3. 8.6338

Soler, R., van der Putten, W. H., Harvey, J. A., Vet, L. E. M., Dicke, M., and Bezemer, T. M. (2012). Root herbivore effects on aboveground multitrophic interactions: patterns, processes and mechanisms. J. Chem. Ecol. 38, 755-767. doi: 10.1007/s10886-012-0104-z

Stearns, S. C. (1992). The Evolution of Life-Histories. Oxford: Oxford University Press.

Strauss, S. Y., and Irwin, R. E. (2004). Ecological and evolutionary consequences of multispecies plant-animal interactions. Annu. Rev. Ecol. Evol. Sci. 35, 435-466. doi: 10.1146/annurev.ecolsys.35.112202.130215

Tawaha, A. M., and Turk, M. A. (2003). Allelopathic effects of black mustard (Brassica nigra L.) on germination and growth of wild barley (Hordeum spontaneum L.). J. Agron. Crop Sci. 189, 298-303. doi: 10.1046/j.1439-037X.2003.00047.x

Thompson, J. N. (2005a). The Geographic Mosaic of Coevolution. Chicago: University of Chicago Press.

Thompson, J. N. (2005b). Coevolution: the geographic mosaic of coevolutionary arms races. Curr. Biol. 15, R992-R994. doi: 10.1016/j.cub.2005.11.046

Travers-Martin, N., and Müller, C. (2008). Matching plant defence syndromes with performance and preference of a specialist herbivore. Funct. Ecol. 22, 1033-1043. doi: 10.1111/j.1365-2435.2008.01487.x

Turk, M. A., and Tawaha, A. M. (2003). Allelopathic effect of black mustard (Brassica nigra L.) on germination and growth of wild oat (Avena fatua L.). Crop Protect. 22, 673-677. doi: 10.1016/S0261-2194(02)00241-7

Utsumi, S., Ando, Y., Craig, T. P., and Ohgushi, T. (2011). Plant genotypic diversity increases population size of a herbivorous insect. Proc. R. Soc. Lond. B Biol. Sci. 278, 3108-3115. doi: 10.1098/rspb.2011.0239

Van Dam, N. M. (2009). Belowground herbivory and plant defenses. Annu. Rev. Ecol. Evol. Sci. 40, 373-391. doi: 10.1146/annurev.ecolsys.110308. 120314 
Van Dam, N. M., and Heil, M. (2011). Multitrophic interactions below and above ground: en route to the next level. J. Chem. Ecol. 99, 77-88. doi: 10.1111/j.13652745.2010.01761.x

Van Dam, N. M., Harvey, J. A., Wackers, F. L., Bezemer, T. M., van der Putten, W. H., and Vet, L. E. M. (2003). Interactions between aboveground en belowground induced responses against phytophages. Basic Appl. Ecol. 4, 63-77. doi: 10.1078/1439-1791-00133

Van Dam, N. M., Raaijmakers, C. E., and van der Putten, W. H. (2004a). Root herbivory reduces growth and survival of the shoot feeding specialist Pieris rapae on Brassica nigra. Entomol. Exp. Appl. 115, 161-170. doi: 10.1111/j.1570-7458.2005.00241.x

Van Dam, N. M., Witjes, L., and Svatos, A. (2004b). Interactions between aboveground and belowground induction of glucosinolates in two wild Brassica species. New Phytol. 161, 801-810 doi: 10.1111/j.1469-8137.2004. 00984.x

Vandegehuchte, M. L., de la Peña, E., and Bonte, D. (2011). Contrasting covariation of above- and belowground invertebrate species across plant genotypes. J. Anim. Ecol. 80, 148-158. doi: 10.1111/j.1365-2656.2010.01766.x

Van der Putten, W. H., Vet, L. E. M., Harvey, J. A., and Wäckers, F. L. (2001). Linking above- and belowground multitrophic interactions of plants, herbivores, pathogens, and their antagonists. Trends Ecol. Evol. 16, 547-554. doi: 10.1016/S0169-5347(01)02265-0

Van Ruijven, J., DeDeyn, G. B., Raaijmakers, C. E., Berendse, F., and van der Putten, W. H. (2005). Interactions between spatially separated herbivores indirectly alter plant diversity. Ecol. Lett. 8, 30-37. doi: 10.1111/j.1461-0248.2004.00688.x

Wardle, D. A., Williamson, W. M., Yeates, G. W., and Bonner K. I. (2005). Trickledown effects of aboveground trophic cascades on the soil food web. Oikos 111, 348-358. doi: 10.1111/j.0030-1299.2005.14092.x

Wardle, D. A., Yeates, G. W., Williamson, W. M., Bonner, I., and Barker, G. M. (2004). Linking aboveground and belowground communities: the indirect influence of aphids species identity and diversity on a three trophic level soil food web. Oikos 107, 283-294. doi: 10.1111/j.0030-1299.2004.13523.x

Wentzell, A. M., and Kliebenstein, D. J. (2008). Genotype, age, tissue, and environment regulate the structural outcome of glucosinolate activation. Plant Physiol. 147, 415-428. doi: 10.1104/pp.107.115279

Whitham, T. G., Young, W. P., Martinsen, G. D., Gehring, C. A., Schweitzer, J. A., Shuster, S. M., et al. (2003). Community and ecosystem genetics: a consequence of the extended genotype. Ecology 84, 559-573. doi: 10.1890/00129658(2003)084[0559:CAEGAC]2.0.CO;2

Wichmann, M. C., Alexander, M. J., Hails, R. S., and Bullock, J. M. (2008). Historical distribution and regional dynamics of two Brassica species. Ecography 31, 673684. doi: 10.1111/j.1600-0587.2008.05564.x

Wittstock, U., Agerbirk, N., Stauber, E. J., Olsen, C. E., Hippler, M., MitchellOlds, T., et al. (2004). Successful herbivore attack due to metabolic diversion of a plant chemical defense. Proc. Natl. Acad. Sci. U.S.A. 101, 4859-4864. doi: 10.1073/pnas.0308007101
Wolfe, L. M., Elzinga, J. A., and Biere, A. (2004). Increased susceptibility to enemies following introduction of the invasive plant Silene latifolia. Ecol. Lett. 7, 813-820. doi: 10.1111/j.1461-0248.2004.00649.x

Wurst, S. (2010). Effects of earthworms on above- and belowground herbivores. Appl. Soil Ecol. 45, 123-130. doi: 10.1016/j.apsoil.2010.04.005

Wurst, S., Langel, R., Rodger, S., and Scheu, S. (2006). Effects of belowground biota on primary and secondary metabolites in Brassica oleracea. Chemoecology 16, 69-73. doi: 10.1007/s00049-005-0328-2

Wurst, S., Van Dam, N. M., Monroy, F., Biere, A., and van der Putten, W. H. (2008). Intraspecific variation in plant defense alters effects of root herbivores on leaf chemistry and aboveground herbivore damage. J. Chem. Ecol. 34, 1360-1367. doi: 10.1007/s10886-008-9537-9

Yang, J. W., Yi, H.-S., Kim, H., Lee, B., Lee, S., Him, S. Y., et al. (2011). Whitefly infestation of pepper plants elicits defence responses against bacterial pathogens in leaves and roots and changes the below-ground microflora. J. Ecol. 99, 46-56. doi: 10.1111/j.1365-2745.2010.01756.x

Zangerl, A. R., and Berenbaum, M. R. (1993). Plant chemistry, insect adaptations to plant chemistry, and host plant utilization patterns. Ecology 74, 47-54. doi: $10.2307 / 1939500$

Zangerl, A. R., and Berenbaum, M. R. (2005). Increase in toxicity on an invasive weed after reassociation with its coevolved herbivore. Proc. Natl. Acad. Sci. U.S.A. 102, 15529-15532. doi: 10.1073/pnas.0507805102

Zangerl, A. R., Stanley, M. C., and Berenbaum, M. R. (2008). Selection for chemical trait remixing in an invasive weed after reassociation with a coevolved specialist. Proc. Natl. Acad. Sci. U.S.A. 105, 4547-4552. doi: 10.1073/pnas. 0710280105

Conflict of Interest Statement: The authors declare that the research was conducted in the absence of any commercial or financial relationships that could be construed as a potential conflict of interest.

Received: 31 May 2013; accepted: 11 October 2013; published online: 28 November 2013

Citation: van Geem M, Gols R, van Dam NM, van der Putten WH, Fortuna $T$ and Harvey JA (2013) The importance of aboveground-belowground interactions on the evolution and maintenance of variation in plant defense traits. Front. Plant Sci. 4:431. doi: 10.3389/fpls.2013.00431

This article was submitted to Plant-Microbe Interaction, a section of the journal Frontiers in Plant Science.

Copyright (C) 2013 van Geem, Gols, van Dam, van der Putten, Fortuna and Harvey. This is an open-access article distributed under the terms of the Creative Commons Attribution License (CC BY). The use, distribution or reproduction in other forums is permitted, provided the original author(s) or licensor are credited and that the original publication in this journal is cited, in accordance with accepted academic practice. No use, distribution or reproduction is permitted which does not comply with these terms. 